\title{
Research Article \\ Textile UWB Antenna with Metamaterial for Healthcare Monitoring
}

\author{
S. Parameswari $\mathbb{D}^{1}$ and C. Chitra ${ }^{2}$ \\ ${ }^{1}$ Department of Electronics and Communication Engineering, Kalasalingam Institute of Technology, Krishnankoil, \\ Tamilnadu 626126, India \\ ${ }^{2}$ Department of Electronics and Communication Engineering, PSNA College of Engineering and Technology, Dindigul, \\ Tamilnadu 624622, India \\ Correspondence should be addressed to S. Parameswari; parameshkannan1982@gmail.com
}

Received 21 October 2021; Revised 6 November 2021; Accepted 23 November 2021; Published 13 December 2021

Academic Editor: Trushit Upadhyaya

Copyright (C) 2021 S. Parameswari and C. Chitra. This is an open access article distributed under the Creative Commons Attribution License, which permits unrestricted use, distribution, and reproduction in any medium, provided the original work is properly cited.

\begin{abstract}
A new metamaterial-based UWB band-notched textile antenna for body area network (BAN) with an operational frequency range of $3 \mathrm{GHz}$ to $11 \mathrm{GHz}$ is created in this paper. The ultra-ide band (UWB) frequency band is covered by the antenna (3.1 GHz to $10.6 \mathrm{GHz}$ ). The antennas are smaller because of the usage of denim (jeans) material, which has a permittivity of 1.67 . To increase the impedance transmission capacity, the ground plane is reduced to a partly rectangular conductive substance. The hexagonal cut on the bottom side is utilised to boost bandwidth by enhancing the electric field dispersion at the edges. The fabrication is built of a $1 \mathrm{~mm}$ thick denim (jeans) substrate, and the feed is a traditional microstrip feed. The return loss and gain characteristics of the proposed antenna are investigated. The performance of a specified antenna is investigated step by step with variable feed length, feed breadth, and substrate properties.
\end{abstract}

\section{Introduction}

Textile antennas are the radiating components used with sensors in body area network connections, such as individuals in hospitals, ICU patients, and report sharing from the patient's position to the doctor's location. The data might be sent promptly in such instances. As a consequence, a short-range communication antenna with a high data rate is needed. Wearability [1] taking up less space $[2,3]$, body compatibility [4], less radiation absorption [5], less field propagation to the human body [6], and high field strength in a particular direction [7] are the most notable features of the material receiving antenna. The dielectric constant of the substrate materials is perhaps the most important factor. This has an effect on the receiving wire's display at specified recurrences. The researchers [1] employed Cordura and Taffeta fabrics, with the first serving as a conductive component and the latter as a substrate component. Fabrication, on the contrary, is a challenge. The team Dona et al. [8] investigated the ultrawide band antenna's performance using different substrates. Based on the findings, jeans material seems to be a potential element for use as a substrate in antennas. A group of experts developed a radio antenna for the use of green distributed computing on a polymer substrate in [9].

A circular patch antenna was built using a variety of materials, including Rogers, flannel, and polyester, and a similarity analysis was undertaken to discover the best one [10]. Using conductive threads and a textile substrate, a totally textile antenna was produced [11]. With permittivity and loss tangent values of 3 and 0.004 , respectively, polydimethylsiloxane (PDMS) substrate has lately emerged as a feasible element in the fabrication of antennas. Shikder and Arifin [12] looked at several UWB antenna designs and tried to enhance bandwidth characteristics [12]. An icon shape was used in their design, and a power shape icon was also made for the use of wireless body area network (WBAN). For body-centered 
network connection, a smart-textile-based suitable communication system was developed [13].

The textile component was unaffected by the system's hardware components. The new technology offers a better degree of comfort, especially when it comes to remote monitoring of ill and elderly persons at home. The work was the first of its type of integrated wearable system in the indoor environment, according to the authors' knowledge. A self-contained hand-held energy harvester with a $464.5 \mathrm{MHz}$ operating frequency was built [14]. In the suggested system, two energy harvesters were shown. One produced DC power and a carrier signal, while the other drove the tags. The Internet of Things was the system's major application (IoT). The researchers utilised a two-way talk radio to demonstrate their wearable material antenna [15-20]. A wearable radio frequency identification (RFID) tag has been developed. Wearable RFID tags that were previously created were passive in the sense that the battery was only placed on the tag, and the reader range was similarly restricted to $4 \mathrm{~m}$. The circular patch antenna, on the contrary, outweighs these drawbacks. A monopole antenna was used to send and receive the RF plasma [21-25]. This investigation looked on the use of a more modest antenna and material as a means of increasing transmission capacity [26-30].

\section{Resources and Techniques}

2.1. Resources. A jeans (denim) substrate with a thickness of $2 \mathrm{~mm}$ and a dielectric constant of 1.67 is used to make the proposed receiving antenna. The planned radio wire is $36 \times 29 \mathrm{~mm}$ in size. Copper tape in the adhesive form, a distinct conductive substance with a thickness of $0.75 \mathrm{~mm}$, was employed as the radiating element. A circular complementary split ring resonator is placed in the middle of the radiating patch to provide band notch functionality in the UWB band (CSRR). The removal of the copper tape is featured in CSRR throughout the patch form.

2.2. Techniques. Gupta et al. established the antenna resonant technique to test the dielectric reliability of the jeans material (2010). As a result, a standard antenna with UWB band dimensions is built utilising similar jean's substrate and copper tape-based leading component components, and the return loss is measured. The computed return loss is compared to the calculated value. The return loss comparison is then repeated after changing the dielectric value and loss tangent of the same antenna. The dielectric and loss tangents are compared and changed in turn until the measured and simulated return loss results coincide. The dielectric and loss tangent values of the jeans material are 1.67 and 0.0035 , respectively, according to this approach.

As part of the antenna's progression, a rectangularshaped patch with a microstrip feed has been designed. On the upper layer, there are two rings (inner and outer rings). A two-opposite-C shape is the CSRR form. Additionally, the design incorporates truncation to increase current flow at the bottom corners. The magnetic field is spread equally over the antenna body because the rectangular microstrip feed is situated in the middle of the antenna element. To boost bandwidth, a half-shaped ground plane has been constructed underneath the jeans substrate. A rectangular slot is inserted into the half-shape ground plane to increase bandwidth (Figures 1 and 2). Figure 3 depicts the dimensional characteristics of the UWB antenna with CSRR. Figure 4 depicts the construction of the intended antenna prototype.

The unit cell model is depicted in Figure 5. The resonance frequency due to CSRR is calculated from the equations as follows [18-23]:

$$
\begin{aligned}
f_{\mathrm{CSRR}} & =\frac{1}{2 \pi \sqrt{L_{\mathrm{CSRR}}} C_{\mathrm{CSRR}}}, \\
C_{\mathrm{CSRR}} & =\frac{N-1}{2}[2 L-(2 N-1)(W+S)] C_{0}, \\
C_{0} & =\varepsilon_{0} \frac{\left(K \sqrt{1-K^{2}}\right)}{K(k)}, \\
k & =\frac{(s / 2)}{w+(s / 2)}, \\
L_{\mathrm{CSRR}} & =4 \mu_{0}[L-(N-1)(S+W)]\left[\ln \left(\frac{0.98}{\rho}\right)+1.84 \rho\right], \\
\rho & =\frac{(N-1)(W+S)}{1-(N-1)(W+S)},
\end{aligned}
$$

where $L$ denotes the length of CSRR and $W$ denotes its width, $S$ is the distance between the two rings, and $N$ denotes the number of rings in CSRR. $2.25 \mathrm{GHz}$ was found to be the predicted resonance frequency.

\section{Results and Discussion}

Figure 6 depicts an analysis of the antenna's return loss performance. Without CSRR, the planned antenna has a return loss of $-30 \mathrm{~dB}$ and a bandwidth of $5 \mathrm{GHz}$. The CSRR antenna has a $-55 \mathrm{~dB}$ return loss and a $7.6 \mathrm{GHz}$ bandwidth. The results of the return loss with CSRR were shown to be superior to the results of the return loss without CSRR. The design was subjected to the parametric study in order to get optimal results in the relevant design. The following are the details of the research.

Table 1 shows how various designs are analyzed during the various processes involved in the CSRR.

The CSRR design placed in the patch's core effects the resonance at $2.25 \mathrm{GHz}$ theoretically and at $2.45 \mathrm{GHz}$ actually.

A performance comparison of the antenna design was possible by switching the substrate to silk, cotton, FR4, and the recommended denim material. It is clear from the research (Figure 7) that the jeans material has a wider bandwidth than other materials.

It is clear from the graph (Figure 8) that the feed length has an impact on the return loss. 


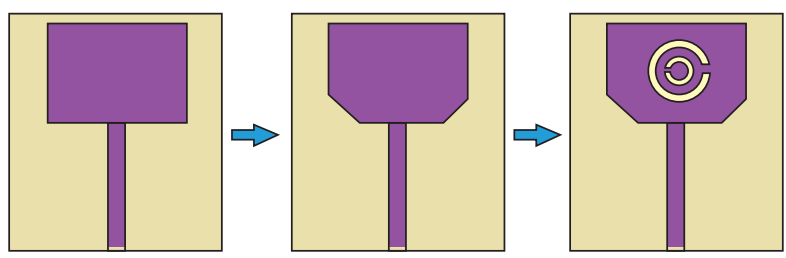

Figure 1: Evolution of the top side of the antenna.

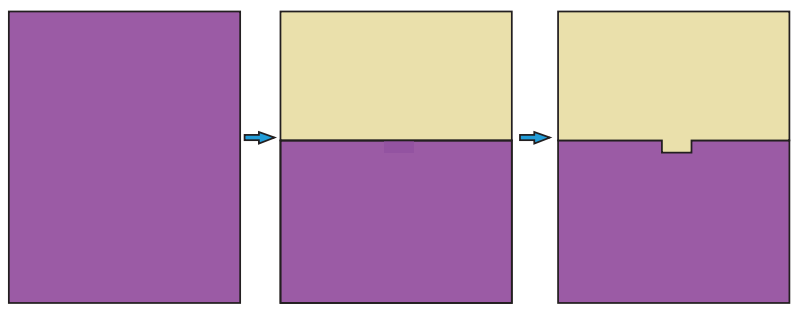

FIGURE 2: Evolution of the bottom side of the antenna.
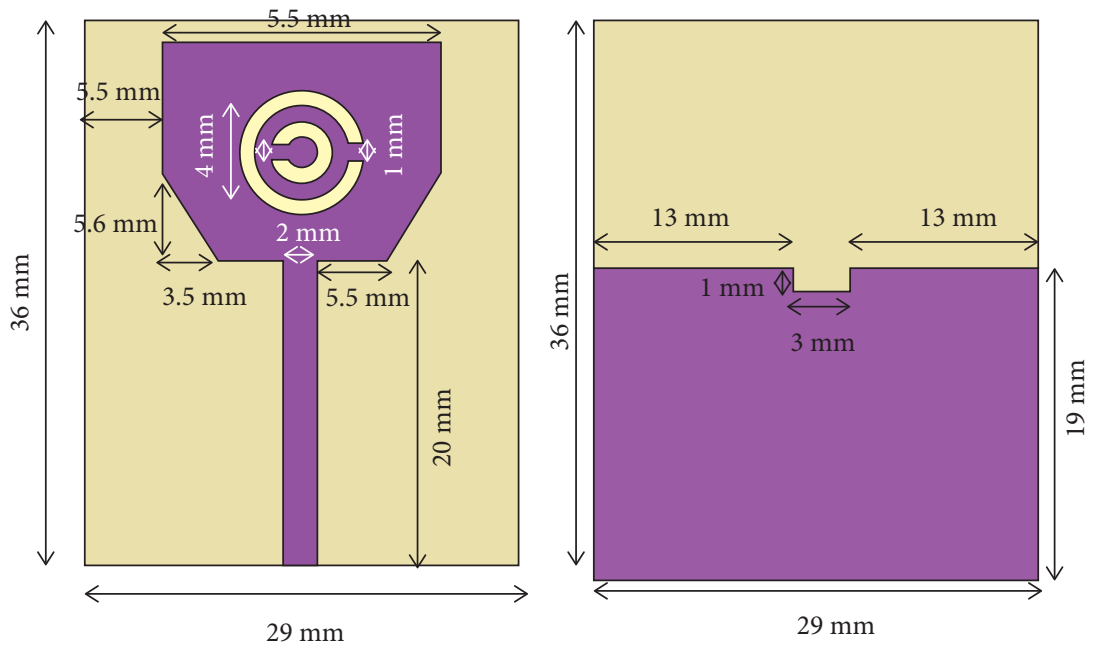

FIgURe 3: Dimensional details of the UWB antenna with CSRR. (a) Top layer. (b) Bottom layer.

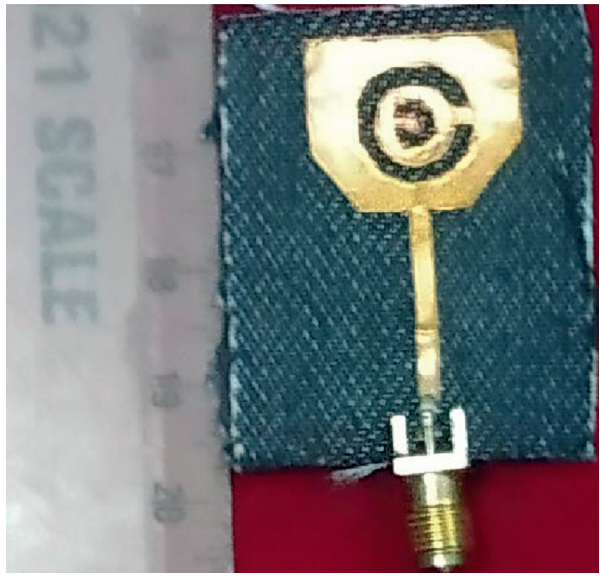

(a)

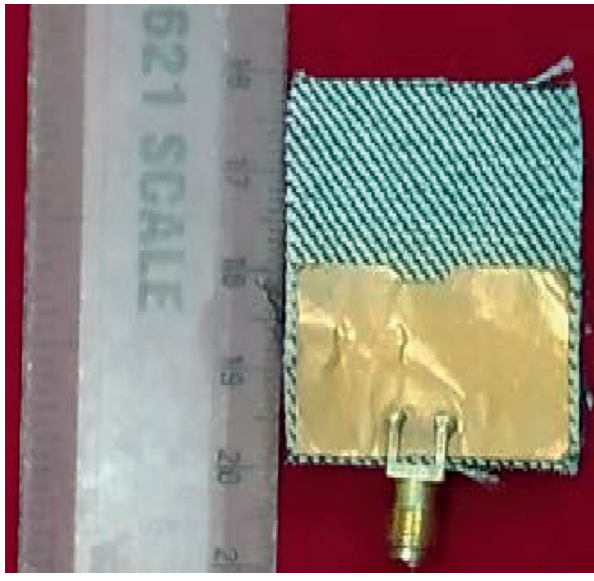

(b)

FIgURE 4: Fabrication of the prototype. 


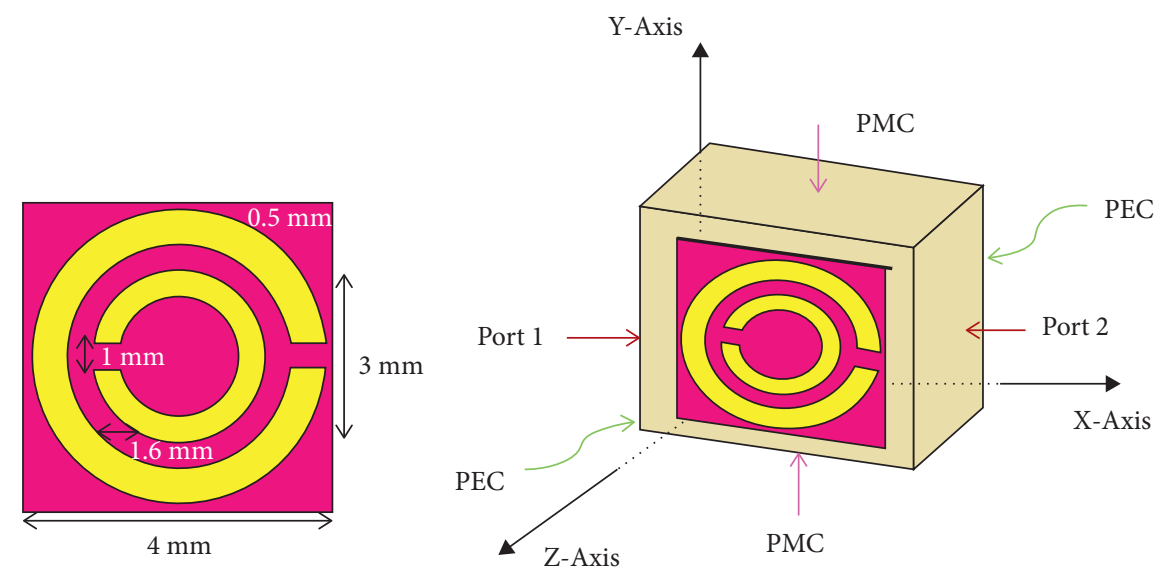

Figure 5: Unit cell model.

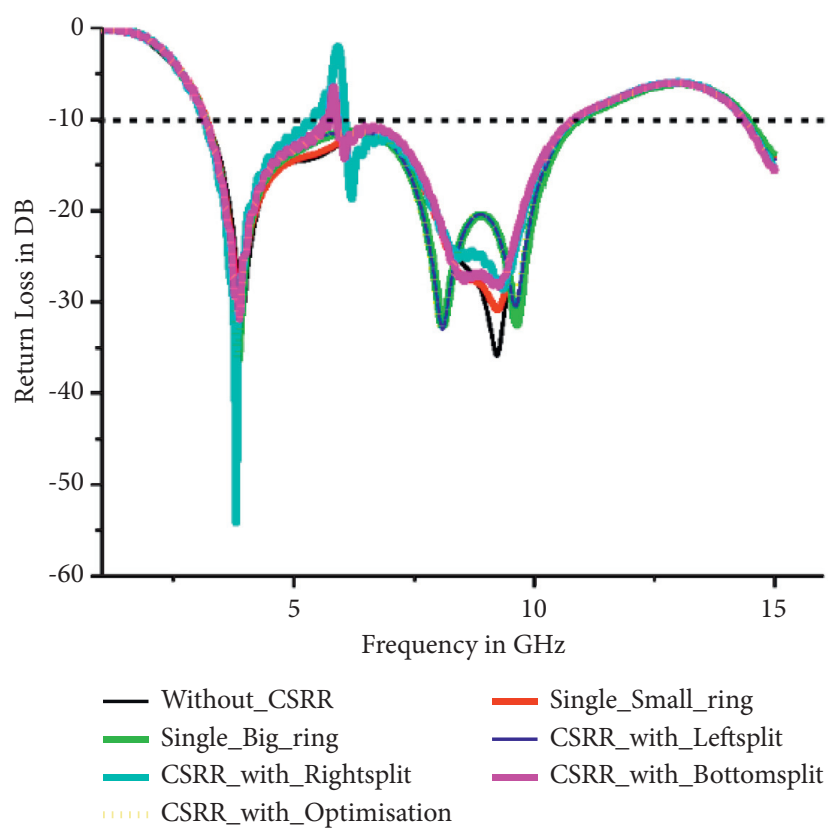

FIgURE 6: Effect of CSRR.

TABLE 1: CSRR optimization outcomes' performance table.

\begin{tabular}{lccc}
\hline S. no & Modification & Return loss & Operating frequency $(\mathrm{GHz})$ \\
\hline 1 & Without CSRR & $-27 \mathrm{~dB}$ & 3.21 \\
2 & Single inner ring & $-33 \mathrm{~dB}$ & 5.12 \\
3 & Single outer ring & $-35 \mathrm{~dB}$ & 6.21 \\
4 & CSRR left split & $-42 \mathrm{~dB}$ & 6.67 \\
5 & CSRR right spilt & $-44 \mathrm{~dB}$ & 7.78 \\
6 & With CSRR & $-45 \mathrm{~dB}$ & 9.78 \\
\hline
\end{tabular}

The bandwidth and resonance frequency of the antenna are also controlled by feed width and location. The research was completed, and the results are given in Figures 9 and 10.

Because the antenna is employed in the UWB regime, the major goal of this research is to improve the antenna's bandwidth. As a consequence, behind the jeans substrate, a biased is implanted. Furthermore, as shown in Figure 11, the choice of one-sided is determined by a parameter analysis of complete ground, half ground, and three-quarter ground planes.

The rectangular area on the ground surface was used to show the increased transmission capacity for the antenna that was envisaged, with the current thickness in the feed district being greater (Figure 12). 


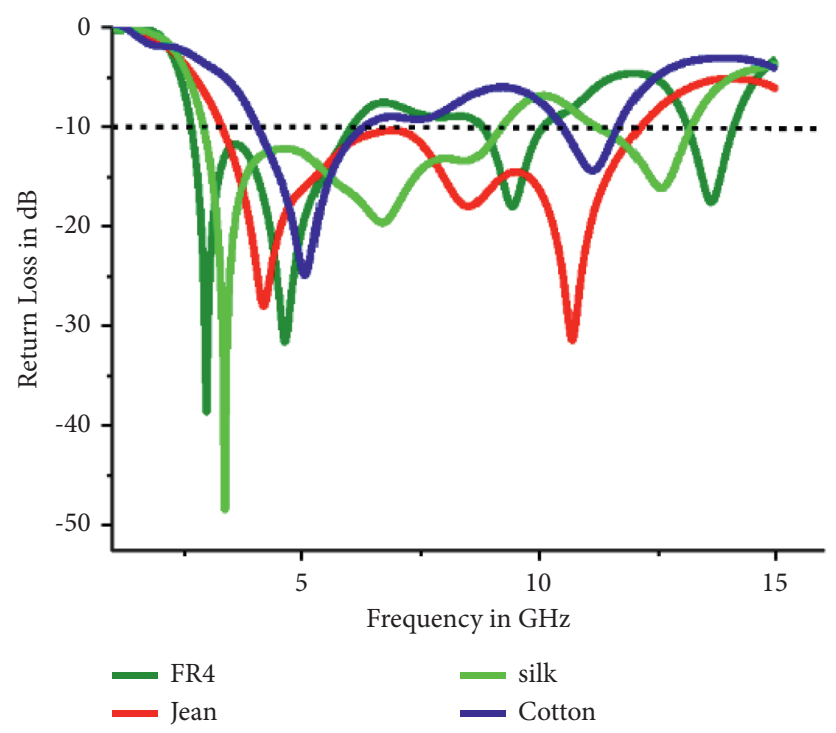

Figure 7: Effect of substrate material.

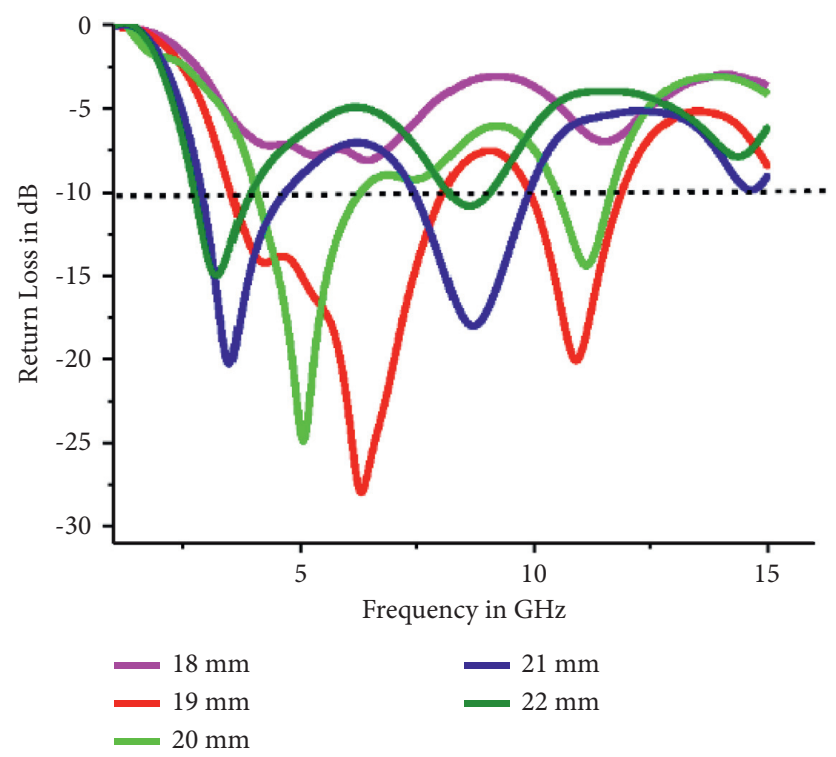

Figure 8: Effect of feed length.

Because the goal of this work is to enhance bandwidth, the patch form has a truncation in its structure, as shown in Figure 13, which also helps to improve bandwidth.

Figure 14 shows the testing setup in the anechoic chamber and with the network analyzer. Figure 15 depicts both simulated and measured return loss results. It is obvious that the suggested antenna design in the UWB range has effectively accomplished bandwidth augmentation.
The simulated and observed $\mathrm{H}$ and $\mathrm{E}$ fields were also obtained as in the needed amount of current and voltage, respectively, from Figures 16 and 17. The group delay of the transmitted signal of the whole operation band measured is measured and is shown in Figure 18.

The re-enacted and estimated aftereffects of a created UWB material-receiving antenna using jeans as a substrate are shown in Table 2. 

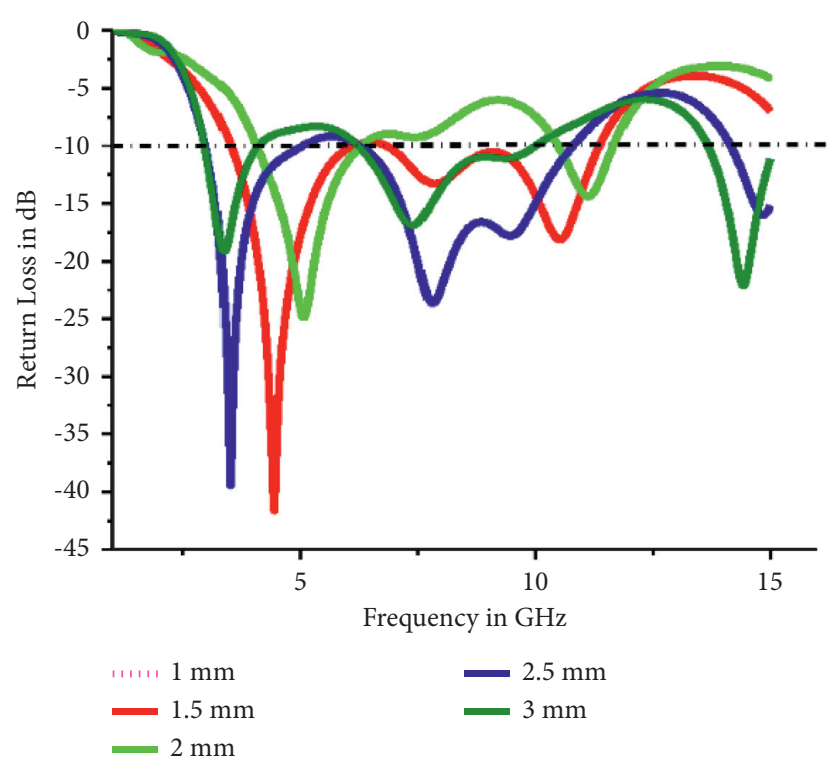

Figure 9: Effect of feed width.

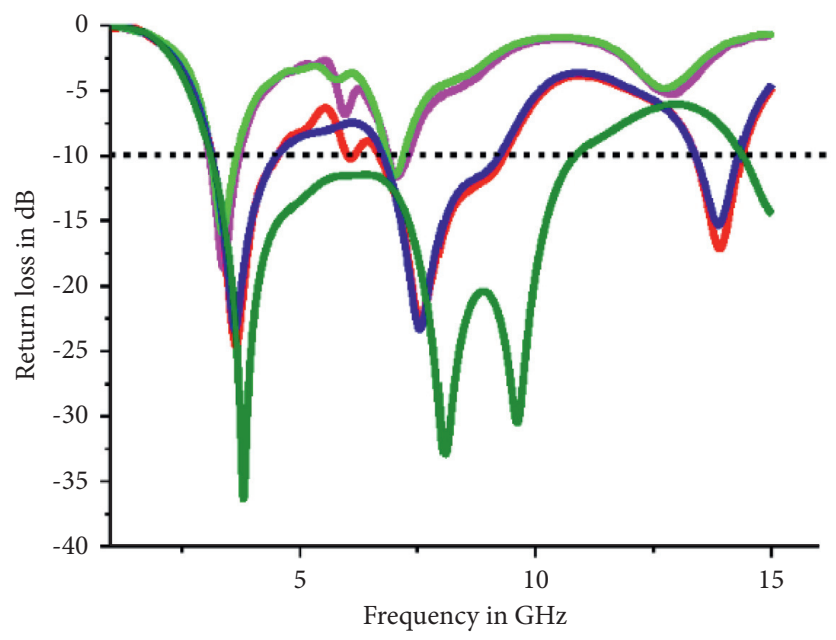

_ feed_at_extream_left

_ feed_at_left_from_center

— feed_at_extream_right_edge

_ feed_at_right_from_center

_ Optimised_position

Figure 10: Effect of position of the feed. 


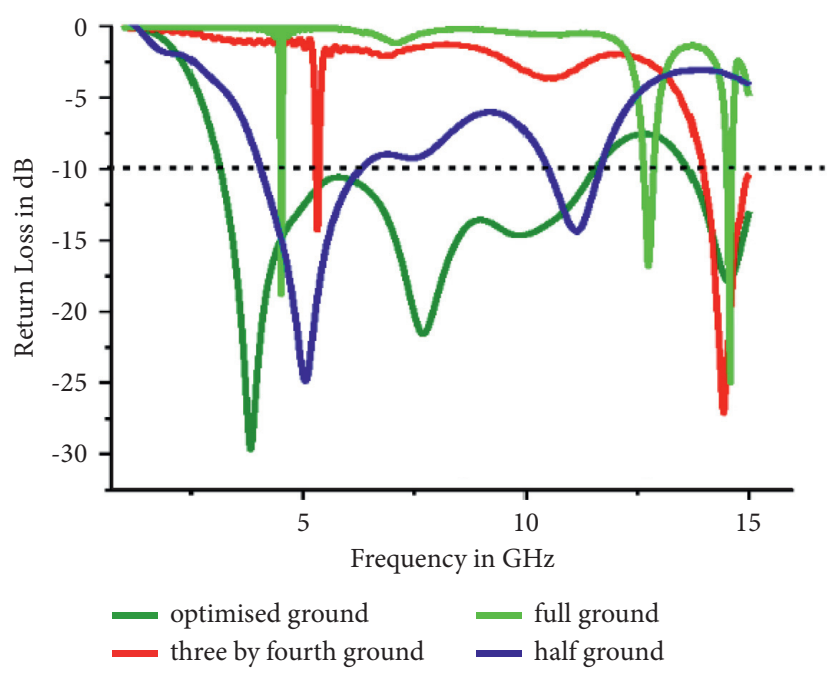

Figure 11: Effect of the ground plane.

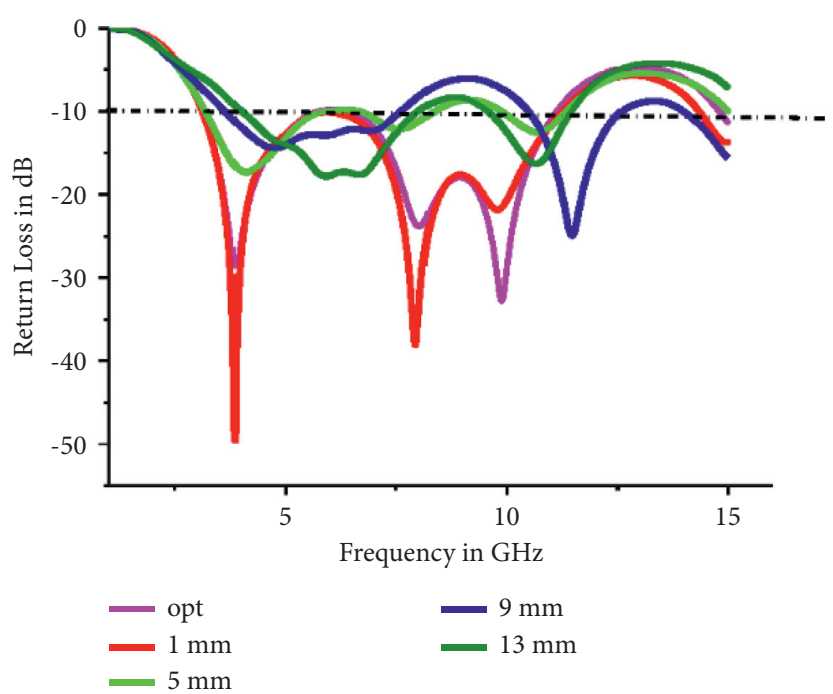

Figure 12: Effect of slot length in the ground. 


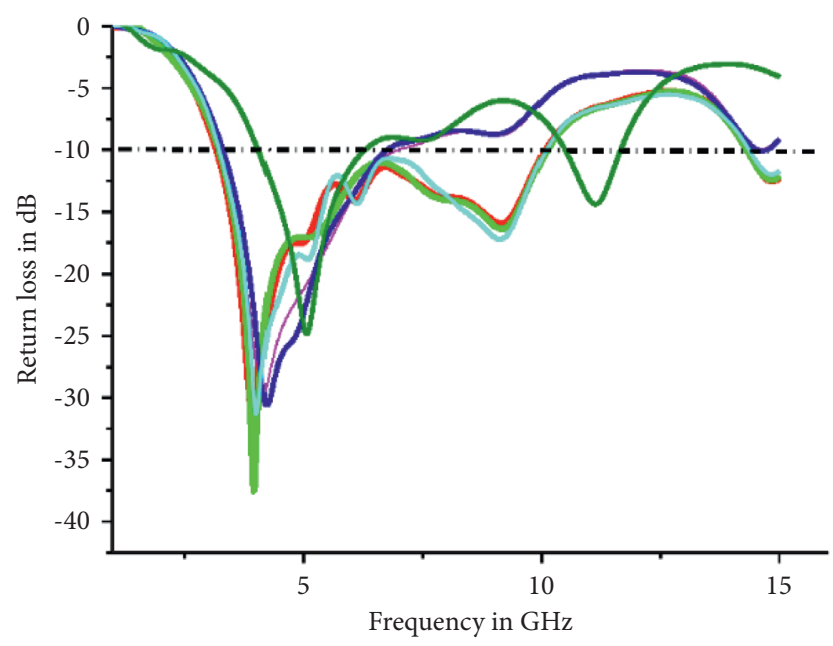

- Without truncation

- Truncation_at_left_side

_ At_right_side_bottom

_ Right_side_top

_ left_side_bottom_right_side_top

— left_and_right_side_bottom

Figure 13: Effect of truncation cut on patch.

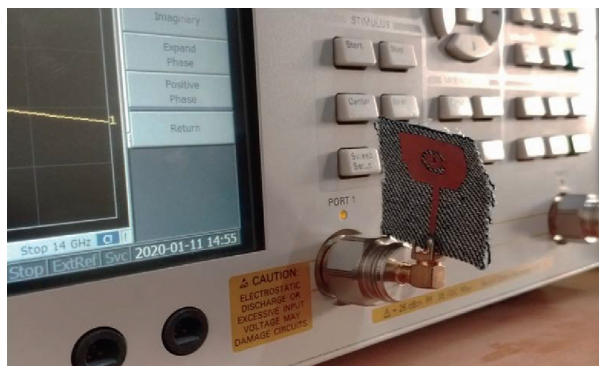

FIGURE 14: Testing of prototype.

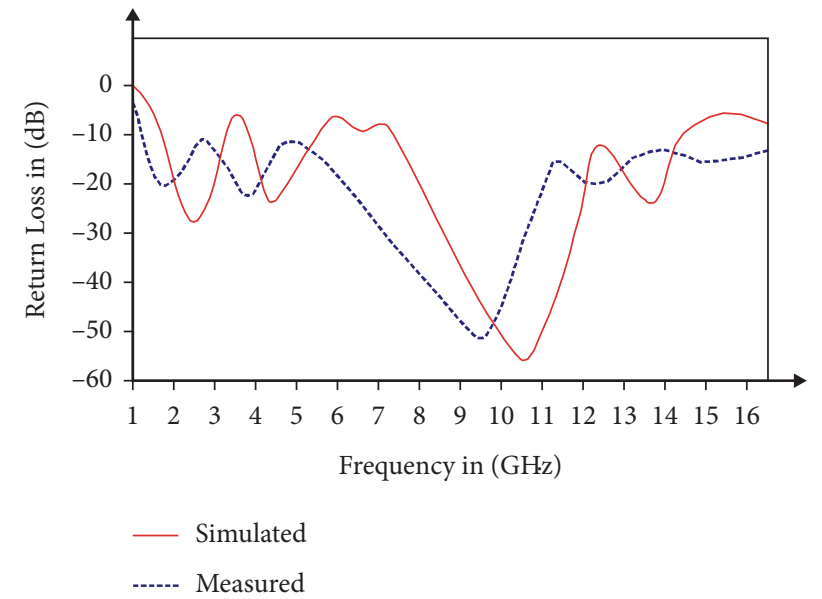

FIGURE 15: Simulated and measured S-parameters. 


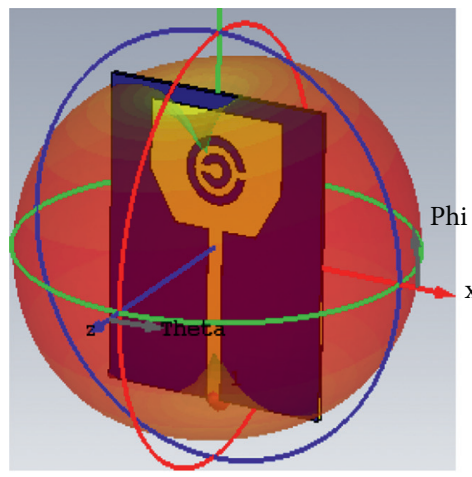

$\mathrm{dBA}(\mathrm{m})$ ine width
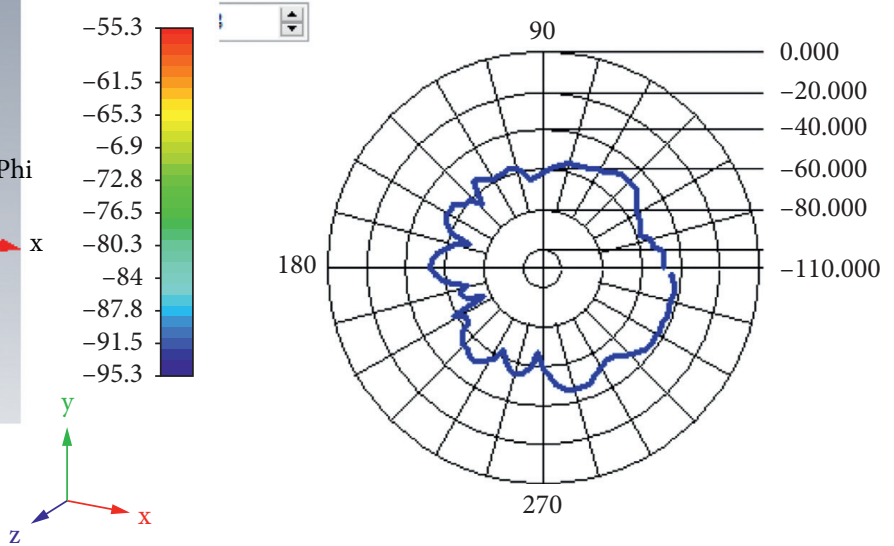

Figure 16: Simulated 3D and measured 2D H field.
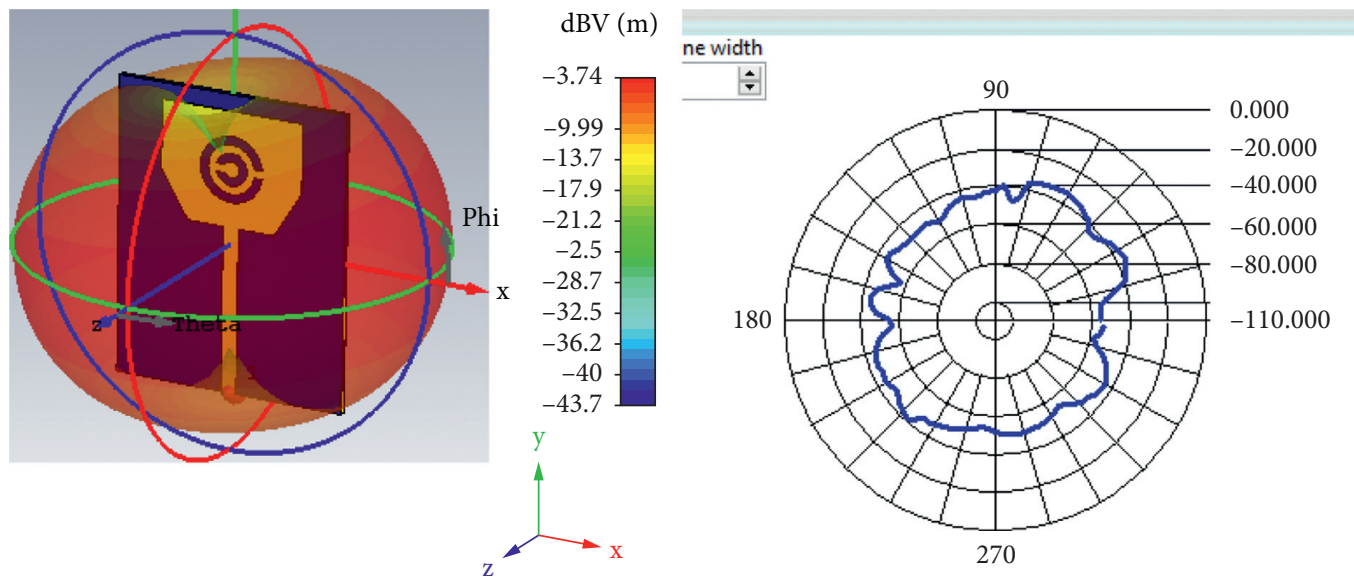

FIGURE 17: Simulated 3D and measured 2D E field.

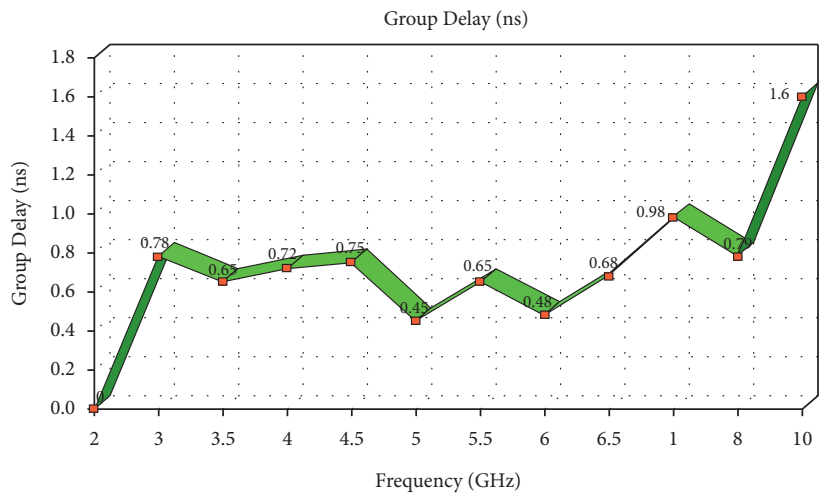

Figure 18: Group delay.

TABLE 2: Reproduced and measured results of the proposed antenna.

\begin{tabular}{lccc}
\hline S. no & Parameter & Simulated & Measured \\
\hline 1 & $\mathrm{~S}_{11} \mathrm{~dB}$ & $-55.15 \mathrm{~dB}$ & $-51.34 \mathrm{~dB}$ \\
2 & VSWR & 1.34 & 1.29 \\
3 & Impedance & $49 \Omega$ & $48.15 \Omega$ \\
4 & Gain & $7.20 \mathrm{dBi}$ & $6.97 \mathrm{dBi}$ \\
5 & Bandwidth & $7.62 \mathrm{GHz}$ & $7.23 \mathrm{GHz}$ \\
6 & Operating frequency & $10.6 \mathrm{GHz}$ & $9.78 \mathrm{GHz}$ \\
\hline
\end{tabular}


TABLE 3: Similarity of the planned antenna to documented UWB antennas.

\begin{tabular}{lccccccc}
\hline S. no & Reference & $\mathrm{S}_{11} \mathrm{~dB}$ & VSWR & Operating frequency $(\mathrm{GHz})$ & Gain $(\mathrm{dBi})$ & Bandwidth $(\mathrm{GHz})$ & Impedance $(\Omega)$ \\
\hline 1 & {$[7]$} & -22.78 & 1.23 & 5.25 & 6.11 & 4.57 & 46 \\
2 & {$[24]$} & -25.12 & 1.34 & 5.73 & 6.28 & 6.58 & 47 \\
3 & {$[20]$} & -30.23 & 1.24 & 7.34 & 7.01 & 6.15 & 4.75 \\
4 & {$[12]$} & -29.72 & 1.31 & 8.62 & 7.20 & 7.62 & 47 \\
5 & Proposed design & -45.15 & 1.35 & 10.6 & 49 \\
\hline
\end{tabular}

In terms of return loss and VSWR, operating frequency and impedance, and bandwidth and fain, Table 3 compares the predicted wearable material UWB antenna to newly specified UWB receiving antennas.

\section{Conclusions}

This paper proposes, builds, and simulates a tiny and compact textile ultrawideband antenna that covers the ultrawideband (UWB) band $(3.1 \mathrm{GHz}$ to $10.6 \mathrm{GHz})$. Metamaterial and the textile material jeans, with a permittivity of 1.67, are used to reduce the antenna's size. The ground plane is partly decreased to improve the impedance bandwidth. By changing the distribution of electric fields at the edges, the CSRR is utilised to extend bandwidth. The fabrication takes place on a $2 \mathrm{~mm}$ thick denim substrate, using a normal microstrip feed. The return loss and gain attributes of the built antenna have been determined to be satisfactory. In short-range specialised devices, the predicted UWB antenna layout may be used. Because the substrate is jeans, a textile material, the antenna may be utilised for body area networks (BAN). Later on, the antenna material might be turned into conductive fabric, transforming it into a wearable antenna.

\section{Data Availability}

The data used to support the findings of the study are available from the corresponding author upon reasonable request.

\section{Conflicts of Interest}

The authors declare that there are no conflicts of interest.

\section{Acknowledgments}

The supports of Mepco Schelnk college of Engineering, Sivakasi, for antenna return loss and radiation pattern measurements are highly appreciated.

\section{References}

[1] G. Indumathi and J. Bhavithra, "Wearable textile antenna for indoor applications," in Proceedings of the International Conference on Inventive Communication and Computational Technologies, (ICICCT 2017), Coimbatore, India, March 2017.

[2] M. A. R. Osman, M. K. A. Rahim, M. F. Ali, N. A. Samsuri, and M. R. Kamarudin, "Compact fully textile UWB antenna for monitoring applications," in Proceedings of the Asia-Pacific Microwave Conference, pp. 1438-1441, Melbourne, Australia, December 2011.
[3] B. Sanz-Izquierdo, J. C. Batchelor, and M. I. Sobhy, "Compact UWB wearable antenna," in Proceedings of the 2007 Loughborough Antennas and Propagation Conference, Loughborough, UK, April 2007.

[4] S. Hassan and S. H. Shehab, "Evaluation of an ultra wideband (UWB) textile antenna in the vicinity of human body model for WBAN applications," in Proceedings of the IEEE International WIE conference on Electrical and Computer Engineering(WIECON-ECE), pp. 195-198, 978-1-4673-8786-6, Dhaka, Bangladesh, December 2015.

[5] P. J. Soh, G. A. E. Vandenbosch, F. H. Wee et al., "SAR evaluation of ultra wideband (UWB) textile antennas," in Proceedings of the 2014 IEEE Topical Conference on Biomedical Wireless Technologies, Networks, and Sensing Systems (BioWireleSS), pp. 13-15, Newport Beach, CA, USA, 2014.

[6] L. A. Yimdjo Poffelie, P. J. Soh, Y. Sen, and G. A. E. Vandenbosch, "A "high-fidelity all-textile UWB antenna with low back radiation for off-body WBAN applications"," IEEE Transactions on Antennas and Propagation, vol. 64, no. 2, pp. 757-760, 2016.

[7] S. P. Oshin and S. Amit, "Design and analysis of high gain UWB textile antenna for wearable application," in Proceedings of the 2017 2nd IEEE International Conference on Recent Trends in Electronics Information \& Communication Technology (RTEICT), Bangalore India, May 2017.

[8] M. Nisha, S. Sai Shweta, G. T. Selvi, and A. M. Bose, "Wearable textile patch antenna: with co-planar waveguide (CPW) feed for medical applications," International Journal of Advances in Science Engineering and Technology, vol. 6, no. 2, 2018, https://iraj.in ISSN(p): 2321 -8991, ISSN(e): $2321-9009$.

[9] H. D. Mustafa1, S. H. Karamchandani1, S. Shubham, S. N. Merchant, and U. B. Desai, "MPTA: "modified polymer textile antennas for green symbiotic cloud communications"” in Proceedings of the IEEE Military Communications Conference, Orlando, FL, USA, November 2013.

[10] M. A. Kango and S. Oza- Rahurkar, "Effect of dielectric materials on UWB antenna for wearable applications," in Proceedings of the IEEE International Conference on Power, Control, Signals and Instrumentation Engineering (ICPCSI2017), pp. 1610-1615ISSN.978-1-5386-0814-2, Chennai, India, September 2017.

[11] A. Kiourti, J. L. Volakis, B. V. B. Roy, Simorangkir, and S. M. Abbas, "UWB antennas on conductive textiles," in Proceedings of the 2016 International Symposium on Antennas and Propagation (APSURSI), pp. 1941-1942ISSN. 978-1-50902886-3, Fajardo, PR, USA, July 2016.

[12] K. Shikder and F. Arifin, "A novel UWB wearable icon-type textile antenna for WBAN applications," in Proceedings of the International Conference on Electrical, Computer and Communication Engineering (ECCE), Cox's Bazar, Bangladesh, February 2017.

[13] Lemey, S. Declercq, F. Declercq, and H. Rogier, "Textile antennas as hybrid energy-harvesting platforms," Proceedings of the IEEE, vol. 102, no. 11, pp. 1833-1857, 2014. 
[14] T. H. Lin, J. Bito, J. G. D. Hester, J. Kimionis, R. A. Bahr, and M. M. Tentzeris, "On-body long-range wireless backscattering sensing system using inkjet-/3-D printed flexible ambient RF energy harvesters capable of simultaneous DC and harmonics generation," IEEE Transactions on Microwave Theory and Techniques, vol. 65, no. 12, pp. 5389-5400, 2017.

[15] S. Lemey, S. Agneessens, P. Van Torre, K. Baes, J. Vanfleteren, and H. Rogier, "Wearable flexible lightweight modular RFID tag with integrated energy harveste," IEEE Transactions on Microwave Theory and Techniques, vol. 64, no. 7, pp. 23042314, 2016.

[16] L. W. Liu, A. Kandwal, H. Shi, Q. S. Cheng, and Cheng, "Wireless power transfer using an RF plasma," IEEE Access, vol. 6, pp. 73905-73915, 2018.

[17] S. Maria Glammi and K. Meena Alias Jeyanthi, "Design of wide band and rectangular microstrip patch antenna for breast tumor detection," International Journal of Recent Technology and Engineering (IJRTE) ISSN: 2277-3878, vol. 7, no. 5S3, 2019.

[18] B. A. Meena, P. T. Selvan, and S. Raghavan, "Compact metamaterial antenna with high directivity for bio-medical systems," Circuits and Systems, vol. 7, pp. 4036-4045, 2016.

[19] B. Anandhi Meena, P. Thiruvalar Selvan, B. Nagaraj, S. Raghavan, S. Suganthi, and V. Karthiyayini, "Novel Splitring resonator antennas for biomedical application," Journal of pure and applied microbiology" special issue on recent research challenges in bio-medical applications, vol. 9, pp. 235242, 2015

[20] B. Anandhi Meena, P. Thiruvalar Selvan, S. Raghavan, and S. Suganthi, "Design of CSRR embedded metamaterial monopole antenna for WiMAX applications," ARPN International Journal of Engineering and Applied Sciences, vol. 10, no. 5, pp. 2214-2216, 2015, ISSN: 1819-6608.

[21] B. Anandhi Meena, P. Thiruvalar Selvan, S. Raghavan, S. Suganthi, and S. Sindhiya, "Effect of ground plane structures in metamaterial inspired monopole antenna," International National Journal of Applied Engineering Research, vol. 10, no. 5, pp. 4777-4780, 2015, ISSN: 0973- 4562.

[22] S. Kannadhasan and R. Nagarajan, "Development of an $\mathrm{H}$-shaped antenna with FR4 for $1-10 \mathrm{GHz}$ wireless communications," Textile Research Journal, vol. 91, 2021 [Impact Factor: 1.926].

[23] K. Meena alias Jeyanthi, E. Thangaselvi, and A. S. Prianga, "Simulation of rectangular microstrip antenna using nylon fabric material," International Journal of Emerging Technology and Advanced Engineering”, vol. 3, no. 1, pp. 645-647, 2013.

[24] M. Klemm, "Member, IEEE, and gerhard troester, senior member," textile UWB antennas for wireless body area networks", IEEE Transactions On Antennas And Propagation, vol. 54, no. 11, pp. 3192-3197, 2006.

[25] K. Shikder and F. Arifin, "Design and evaluation of a UWB wearable textile antenna for body area network," in Proceedings of the 2015 2nd International Conference on Electrical Information and Communication Technologies (EICT), pp. 326-330ISSN-978-1-4673-9257-0, Khulna, Bangladesh, December 2015.

[26] S. A. Holland, D. Baiya, E. Elkhouly, and A. E. Fathy, "Ultra wideband textile antenna development for indoor localization," in Proceedings of the IEEE MTT-S International Microwave Symposium Digest(MTT), Seattle, WA, USAISSN. 978-1-4673-2141-9, Seattle, WA, USA, June 2013.

[27] J. K. Ha, S. H. Jung, M. C. Park, K. H. Lee, and S. E. Yun, “A fully integrated 3-5 GHz UWB RF transceiver for WBAN applications," in Proceedings of the MTT-S International
Microwave Workshop Series on RF and Wireless Technologies for Biomedical and Healthcare Applications (IMWS-BIO) 2013, SingaporeISSN. 978-1-4673-6096-8., Singapore, December 2013.

[28] S. Kannadhasan and R. Nagarajan, "Performance improvement of H-Shaped antenna with zener diode for textile applications," The Journal of The Textile Institute, pp. 1-8, 2021.

[29] S. Parameswari and C. Chitra, "Compact textile UWB antenna with hexagonal for biomedical communication," Journal of Ambient Intelligence and Humanized Computing, 2021.

[30] S. Parameswari and C. Chitra, "Design of H shaped microstrip patch antenna with hexagonal slots for microwave band applications," International Journal of Creative Research Thoughts, 7.97 Impact Factor, Refereed Journal, Peer Journal and Indexed Journal (ISSN: 2320-2882), vol. 8, no. 8, 2020. 